\title{
GOVERNO DAS SOCIEDADES - DIAGNÓSTICO DA SITUAÇÃO EM PORTUGAL
}

\section{Clotilde Passos ${ }^{1}$}

\begin{abstract}
Resumo: O conceito Governo das Sociedades é complexo, multidisciplinar abrange várias áreas da economia e gestão, e está longe de estar devidamente clarificado. Tendo em conta que o mercado $e$ as organizações empresariais estão em constante evolução, adaptação às alterações do meio envolvente, ao risco e à incerteza, este é um tema que requer estudos sistemáticos, para a requerida adequação às novas exigências empresariais. Neste sentido, o principal objetivo deste artigo é contextualizar o conceito e analisar a evolução da sua adoção pelo tecido empresarial Português, recorrendo à revisão da literatura e análise de estudos práticos sobre a sua implementação e, desta forma, contribuir para uma melhor compreensão do tema, reforçando os benefícios da adoção dos seus princípios e recomendações para a organização. Pode concluir-se que as organizações em Portugal têm aderido de forma gradual e crescente ao governo das sociedades com resultados muito positivos.
\end{abstract}

Palavras chave: Governo das sociedades, responsabilidade, transparência.

\begin{abstract}
The Corporate Governance concept is complex, multidisciplinary, encompasses several areas of economics and management, and it is far from being properly clarified. Given that the market and enterprises are in constant evolution, adapting to changes in the environment, risk and uncertainty, this is a subject which requires systematic studies, for the necessary compliance with new entrepreneurial demands. In this scope, the goal of this article is to contextualize the concept and analyze its adoption within the Portuguese entrepreneurial sector, resorting to literature revision and practical studies analysis on its implementation, thus contributing for a better understanding of the topic, reinforcing the benefits for the
\end{abstract}

\footnotetext{
${ }^{1}$ Doutorada em Gestão. Professora do Centro Regional de Viseu da Universidade Católica Portuguesa. E-mail: clotilde.passos@gmail.com
} 
organization in adopting its principles and recommendations. One might conclude that the organizations, in Portugal, adhered gradually and in growing numbers to Corporate Governance with very positive results.

Keywords: Corporate Governance, responsibility, transparency.

\section{INTRODUÇÃO}

O conceito governo das sociedades, teve origem na crise de 1929 nos EUA, ganhou relevância com os trabalhos de Berle e Means em 1932, quando levantaram o clássico problema da Teoria da Agência (Zingales, 1997). O debate sobre Governo das Sociedades só passou a ser relevante, no meio académico, a partir da década de 80 (Marques, 2008). O Governo das sociedades tornou-se uma preocupação central do nosso tempo (Pargendler, 2016). Mas, as evidências empíricas ainda são escassas, por falta de dados adequados Zhong et al. (2017). Em Portugal a adoção do sistema é recente encontrando-se em fase de construção.

O interesse sobre o conceito centra-se em dois grupos de agentes: proprietários (acionistas) e gestores (Santos, 2009; Jensen \& Meckling, 1976 citado por Müller et al. (2016). Os conflitos de interesses, entre estes dois agentes, estão na origem da discussão que tem vindo a ocorrer nesta área e que justifica o interesse crescente do tema e da sua evolução. A principal causa do mecanismo do governo das sociedades é o problema da agência (Naseem et al. 2017).

O processo de globalização da atividade económica levou, a que as organizações sentissem necessidade de adaptar as suas estruturas e processos de tomada de decisões de forma a poderem atender às novas realidades que vêm surgindo no panorama económico (Santos, 2009). Neste sentido foram criadas leis e sistemas, apoiados por princípios e recomendações, para proteger os interesses dos investidores, nivelar parâmetros de segurança, aumentar a transparência da gestão e melhorar a confiança nos mercados de capitais. Neste contexto Portugal não pode alhear-se desta problemática.

O governo das sociedades engloba um conjunto de fenómenos económicos e financeiros distintos e tem sido objeto de um forte interesse público devido à sua aparente importância para a saúde económica das empresas e da sociedade em geral. A adoção de um bom sistema de governo das sociedades é de extrema importância para garantir a transparência da gestão e a confiança por parte dos acionistas e futuros investidores (Marques, (2008); Cosset et al. (2016); Darrat et al. (2016). 
Nesta ordem de ideias, o objetivo deste artigo é contextualizar o conceito e efetuar um diagnóstico da situação em Portugal, no âmbito do acolhimento e aplicação do governo das sociedades. O Estudo desenvolvese em quatro pontos, depois da introdução, efetua-se a revisão da literatura com o objetivo de caraterizar o conceito, as principais bases teóricas e os principais sistemas utilizados. No terceiro ponto efetua-se a análise da situação em Portugal e no ponto quatro finaliza-se com as considerações finais.

\section{REVISÃO DA LITERATURA}

\subsection{Caracterização do conceito governo da sociedade}

O conceito Governo das Sociedades, internacionalmente conhecido por "corporate governance", teve origem nos EUA com o trabalho realizado por Adolph Berle e Gardiner Means, "The Modern Corporation and Private Property", publicado em 1932, quando levantaram o clássico problema da Teoria da Agência. Este trabalho, acabou por ser considerado uma referência para a legislação norte-americana que foi entretanto aprovada (Zingales, 1997). Esta matéria voltou a evidenciar-se na década de 70 como reação a escândalos de corrupção financeira por parte de enumeras sociedades (Moreira el al. 2008). Mas foi com a criação da Comissão Treadway em 1985, pelo Congresso Americano com o intuito de aumentar o combate à fraude, que esta temática ganhou destaque (Pinheiro, 2008).

Este relatório pretende que os responsáveis pela gestão concebam um sistema de controlo interno eficaz, com a criação de um código de conduta e de uma comissão de auditoria que integre profissionais competentes e com conhecimento adequado da atividade desenvolvida (Pires, 2008; Gonçalves, 2008). Esta comissão também criou o Commitee of Sponsoring Organizations (COSO) e desde a sua criação a sua estrutura tem sido incorporada em políticas, normas e regulamentos adotadas por enumeras organizações (Gonçalves, 2008).

Na Europa, a problemática do governo das sociedades desenvolveu-se quando em 1992 surge o relatório Cadbury, na sequência de grandes escândalos financeiros ocorridos em várias empresas do Reino Unido, nomeadamente Maxwell (1991), BCCI e Mirror Grup (1992). Este documento trouxe um importante desenvolvimento ao nível do governo das sociedades e um reconhecimento significativo da auditoria interna (Câmara, 2007). O relatório britânico pretendia que os administradores elaborassem, anualmente, uma declaração sobre a eficácia do sistema de controlo interno, a qual seria apreciada pelo auditor (Mattedi, 2006).

Em 1995 surge o relatório Greenbury que se caracteriza por recomendar o reforço da relação existente entre o conselho de 
administração, a estrutura dos órgãos de administração e suas comissões a divulgação das remunerações nos relatórios anuais e a criação de um comité de remunerações, composto por administradores não executivos. Refere ainda a separação das funções de Presidente do Conselho de Administração e de Presidente da Comissão Executiva (Pires, 2008). Este relatório introduziu o princípio (“comply or explain”), “cumpra ou explique" segundo o qual as empresas devem declarar quais as normas que cumprem e justificar as situações de não-cumprimento. Tal como mencionado por Jones e Pollitt (2003) citado por Silva et al. (2006), o relatório Cadbury foi precursor nalgumas matérias, como sejam a atenção dada ao órgão de administração no processo de tomada de decisão e a importância da constituição de comissões de controlo e muitas das suas recomendações foram incorporadas noutros códigos de "boas práticas", nomeadamente nos Princípios do Governo das Sociedades da OCDE, publicados em 1999.

Ainda em 1995 surge o relatório Hampel, que segundo Cunha e Martins (2007) tenta desenvolver standards elevados de governo das sociedades, destacando a proteção dos investidores e a garantia do bom desempenho das empresas inglesas cotadas em bolsa. Este relatório vem apoiar e reforçar os pressupostos dos relatórios de Cadbury e de Greenbury.

Em 1999 aparece, o relatório Turnbull que acaba por juntar o que de melhor há nos relatórios anteriores. O seu principal objetivo é, assegurar uma boa gestão das empresas centrando a atenção no controlo interno e na gestão de risco (Pires, 2008).

Em 2002, a pedido da União Europeia, um grupo de peritos elaborou o relatório de WinterII, com o título "Um quadro regulamentar moderno para o direito das sociedades". O relatório foi considerado o primeiro estudo sério de harmonização do tema no espaço comunitário (Santos, 2009). O Relatório Winter II pôs em relevo, algumas questões do governo das sociedades e sobre elas tem formulado recomendações que têm vindo a servir de orientação à Comissão Europeia, na produção normativa sobre esta matéria, nomeadamente; a revitalização das assembleias gerais, transparência de atuação dos investidores institucionais, responsabilidade e remuneração dos administradores, papel dos administradores independentes e das comissões do Conselho de Administração e qualidade da informação financeira (Santos, 2009).

O governo das sociedades também mereceu atenção por parte da OCDE, que em 1999 publicou os Princípios de Governo das Sociedades, revistos em 2004. Os princípios mais relevantes são; assegurar a base para um enquadramento eficaz do governo das sociedades; os direitos fundamentais e tratamento equitativo dos acionistas; divulgação de informação, transparência e as responsabilidades do Órgão de Administração que têm servido de orientação para iniciativas legislativas e 
regulamentadoras de vários países comunitários, incluindo Portugal (Marques, 2008). A OCDE sugere que as empresas indiquem no Relatório de Contas se estão ou não a cumprir o código e caso não o cumpram apresentem razões para tal, seguindo a filosofia "comply or explain" (Duarte, 2008). Atualmente, a necessidade de determinar uma estrutura de capital ótima tornou-se mais problemática, bem como importante devido à necessidade de adotar melhores práticas de governo das sociedades (Naseem et al. 2017). Hoje, as estruturas do governo das sociedades são principalmente confrontadas com questões de transparência, produtividade e divulgação eticamente correta da informação (Müller et al. 2016).

A falência da Enron em dezembro de 2001, da WorldCom, Adelhia, Nortel, e eToys em 2002, e na Europa a Ahold, Parmalat, Vivendi Universal e Swissair em 2003, trouxeram para o domínio da opinião pública o debate sobre o governo das sociedades (Darrat et al. 2016), bem como a necessidade de criar mecanismos de combate à fraude, no sentido de restaurar a confiança nos mercados. Em resposta aos escândalos financeiros surge, em 2002, a lei Sarbanes Oxley Act (SOX) que tenta restabelecer a confiança dos investidores no mercado de capitais norteamericano transformando as boas práticas de governo das sociedades em leis (Pires, 2008).

Tanto o relatório Cadbury, (1992) como a OCDE, (2004) sugerem que as boas práticas no que respeita à composição do órgão de administração deverão ser de maioria de administradores não executivos. Segundo Beasley (1996) a presença de administradores não executivos reduz a probabilidade de fraude nos relatórios financeiros. Dechow et al. (1996) argumentam que as empresas com maior proporção de administradores não executivos estão menos propensas a serem investigadas pelas autoridades reguladoras. Ter maior proporção de diretores internos reduz o risco de falência nas organizações (Darrat et al. 2016). Peasnell et al. (2000) e Chtourou et al. (2001) comprovam que a independência do órgão de administração surge associada à redução de práticas fraudulentas de gestão e de resultados. Naseem et al. (2017) concluíram que um órgão de administração com maior número de elementos pode tomar melhores decisões e monitorar mais eficientemente a gestão organizacional.

A OCDE define "corporate governance, como sendo o sistema através do qual as organizações empresariais são dirigidas e controladas. Define uma estrutura específica para a distribuição dos direitos e das responsabilidades dos diferentes participantes na empresa, o conselho de administração, os gestores, os acionistas e outros intervenientes ditam as regras e os procedimentos para a tomada de decisões nas questões empresariais” (www.ocde.pt). Em Portugal a Comissão de Mercados dos Valores Mobiliários (CMVM) define o governo das sociedades como "o sistema de regras e condutas relativo ao exercício da direção e controlo das 
sociedades emitentes de ações admitidas à negociação em mercado regulamentado". Para Zhong et al. (2017) o governo das sociedades é "o design da instituição" que induz ou força a gestão a internalizar o bemestar das partes interessadas. O governo das sociedades é um conceito amplo com um amplo espectro de definições (Müller et al. 2016).

$\mathrm{O}$ governo das sociedades comporta uma vertente interna e uma vertente externa; na primeira, entende-se o conjunto das regras organizativas dentro de cada sociedade cotada; na externa, o controlo externo reporta-se à avaliação sobre o desempenho das sociedades que é feito através do normal funcionamento dos mecanismos de mercado (Santos, 2009).

Como mecanismos de controlo interno, podem salientar-se; a remuneração dos gestores, o padrão acionista, o papel supervisor do endividamento, a auditoria interna e o Conselho de Administração. Fama e Jensen, (1983) citados por Santos (2009) argumentam que o órgão de administração é o mais importante e eficaz mecanismo de controlo, por surgir no topo da estrutura do governo das sociedades. Segundo Darrat et al. (2016) a organização que acaba por ir à falência sofre de uma estrutura deficitária do governo das sociedades bastante antes de decretar falência. O controlo interno, numa primeira fase incidiu mais na importância do controlo e dos riscos operacionais, tendo evoluído para a focalização na gestão de resultados e no reporte inapropriado por parte das sociedades (Martin et al. 2002; Clikeman, 2003 e Hala, 2003). A auditoria externa é outro dos mecanismos de governo das sociedades. As evidências empíricas sugerem que as grandes empresas de auditoria conseguem uma maior eficácia na monitorização da fiabilidade dos relatórios financeiros (Francis et al. 1999; Francis e Kirshnan, 1999 e Kim et al. (2003) citados por Silva et al. (2006). Estas funções, controlo interno e externo, deverão permitir um maior controlo do risco de negócio (Scarbrough et al. 1998; Goodwin e Yeo, 2001; Goodwin, 2003).

\subsection{Base teórica do governo das sociedades}

O estudo realizado por Berle \& Means em 1932, resultou na teoria da agência que deu origem ao conceito, governo das sociedades, e foi a partir desta que grande parte dos modelos e processos têm sido adotados, talvez por contemplar a separação entre a propriedade da empresa e a gestão (Serafim et al. 2010). Segundo estes autores as teorias mais relevantes que fundamentam o governo das sociedades são a Stewardship Theory, a (Agency Theory) e a Resource Dependence Theory, mas os principais desenvolvimentos têm-se centrado na Teoria da Agência $^{2}$, sendo nela que

\footnotetext{
2 - A teoria de agência refere que "uma relação de agência ocorre quando o principal
} delega alguns direitos, por exemplo, direitos sobre a utilização de recursos, a um agente 
grande parte dos modelos e processos de governo das sociedades assentam. O problema de agência é a principal causa do mecanismo do governo das sociedades (Müller et al. (2016); Cosset et al. (2016); Naseem et al. (2017).

A base da Teoria da Agência reside na motivação dos atores individuais para a maximização da sua "utilidade", pelo que a relação entre os acionistas e os gestores será sempre problemática (Santos, 2009). A grande questão reside em saber; como é que os acionistas evitam que os gestores maximizem a sua própria utilidade. Serafim et al. (2010) argumentam que o equilíbrio só se obtém quando os gestores de topo detêm ações das empresas. Segundo Naseem et al. (2017) para mitigar o problema da agência, as organizações podem implementar o código de governo das sociedades.

Estes mecanismos desenvolvidos, para minimizar a possibilidade de perdas associadas ao modo de gestão adotado pela organização, bem como ao controlo exercido sobre os gestores profissionais são designados de Governo das Sociedades.

\subsection{Principais sistemas do governo das sociedades}

Os mecanismos de tomada de decisões e de fiscalização variam de país para país, e dentro de um mesmo enquadramento legal e institucional podem variar de empresa para empresa (Silva et al. 2006). Em geral, o governo das sociedades reflete como o poder é distribuído dentro de uma empresa (Zingales, 1998). Assim, a estrutura de poder se uma organização deve ser um fator determinante para o seu sistema de governo das sociedades e para estabelecer relações entre 0 órgão de direção e todos os stakeholders (Zhong et al. 2017). É frequente identificarem-se dois sistemas principais de governo das sociedades: o sistema continental (ou sistema de controlo interno) e o sistema anglosaxónico (ou sistema de controlo externo ou sistema de controlo pelo mercado), conforme se apresenta na tabela 1 .

que está obrigado através de um contrato (formal ou informal) a representar os interesses do principal em troca de uma remuneração” Serafim et al. (2010) 


\section{Tabela 1}

Principais sistemas do governo das sociedades

\begin{tabular}{|c|c|c|c|}
\hline \multirow{3}{*}{$\begin{array}{l}\text { Sistemas } \\
\text { de } \\
\text { Governo } \\
\text { das } \\
\text { Sociedades }\end{array}$} & $\begin{array}{l}\text { S. anglo - } \\
\text { saxónico } \\
\text { S. de controlo } \\
\text { externo ou } \\
\text { S. de controlo } \\
\text { pelo mercado }\end{array}$ & \multicolumn{2}{|c|}{$\begin{array}{l}\text { Identificado com os EUA, Reino Unido e } \\
\text { os restantes países de influência anglo - } \\
\text { saxónia }\end{array}$} \\
\hline & \multirow{2}{*}{$\begin{array}{l}\text { S. Continental } \\
\text { ou de controlo } \\
\text { Interno }\end{array}$} & \multirow{2}{*}{$\begin{array}{l}\text { É conotado com o } \\
\text { governo das empresas } \\
\text { da Europa Continental } \\
\text { e Japão e subdivide-se } \\
\text { em: }\end{array}$} & $\begin{array}{l}\text { Modelo } \\
\text { Dualista - Dois } \\
\text { órgão com } \\
\text { responsabilidade } \\
\text { no CA }\end{array}$ \\
\hline & & & $\begin{array}{l}\text { Modelo } \\
\text { Monista - Um } \\
\text { órgão com } \\
\text { responsabilidade } \\
\text { no CA }\end{array}$ \\
\hline
\end{tabular}

Fonte: Adaptado de Serafim et al., (2010)

Serafim et al. (2010) defendem um sistema de governo das sociedades baseado em dois conjuntos de práticas; o modelo shareholder ou financeiro, cujo foco central é o interesse do acionista (stokholder); e o modelo stakeholders ou de públicos relevantes, que adota uma visão mais abrangente, enfatizando, a responsabilidade social da organização, como uma rede formal e informal de relacionamento com diversos atores.

Os principais pilares do sistema anglo-saxónico são; as remunerações dos gestores, em que a remuneração variável é a sua principal componente, e o seu montante por norma indexado aos resultados ou à cotação da empresa. Zhong et al. (2017) referem que o governo das sociedades induz o gestor a ajustar os pagamentos salariais para o nível de "salário de eficiência". Outro pilar consiste na ampla divulgação de informação ao mercado de capitais e na auditoria externa dessa informação; a estrutura e o modo de funcionamento do Conselho de Administração é outro pilar (Darrat et al. 2016). Este órgão é tipicamente integrado por dois tipos de administradores. Os chamados administradores internos (insiders) e os administradores externos (outsiders). Os primeiros são, em regra, executivos e frequentemente fizeram carreira na empresa, ao passo que os segundos são, por norma, não executivos e sem ligação à estrutura interna da empresa (Serafim et al. 2010).

Na Europa continental, a estrutura de propriedade é tida como um mecanismo determinante e crucial da estratégia da empresa e do seu desempenho. Aqui a propriedade está longe de ser tão difusa quanto nos países anglo-saxónicos, sendo frequente a existência de acionistas, particularmente famílias, com posições relevantes (Silva et al. 2006). 
Segundo estes autores, o controlo dos gestores pelos maiores acionistas é, um elemento fundamental deste modelo. Os principais acionistas controlam (internamente) a gestão e tomam as principais decisões estratégicas da empresa. É também frequente que os próprios acionistas principais tenham assento nos órgãos de administração ou então façam eleger pessoas da sua confiança.

No que diz respeito à estrutura dos órgãos de administração, em múltiplos países da Europa continental predomina o modelo dualista, caracterizado pela existência de dois órgãos com responsabilidade pela administração da empresa. Neste modelo as funções de supervisão e de gestão estão separadas, a primeira está entregue a um Conselho Geral e a segunda à Direção (Duarte, 2008). O modelo dualista é orientado para os stakeholders, apresenta maior transparência e participação de “independentes", na supervisão dá ênfase à implementação do modelo de governo das sociedades e de gestão e ao "crescimento sustentado" e confere a separação entre órgão de supervisão e órgão executivo (Marques, 2008). Segundo Serafim et al. (2010), o modelo dualista visa criar uma estrutura intermédia entre a assembleia-geral e os gestores executivos (direção), a qual além de outras funções deve desempenhar um papel de fiscalização e de controlo dos administradores executivos e dos acionistas.

No modelo Monista, a estrutura dos órgãos da administração são compostos simultaneamente por membros executivos e membros não executivos (Duarte, 2008). O modelo Monista é unitário, orientado para os acionistas, para a concentração na mesma pessoa de funções executivas e de supervisão e para a "não independência" da supervisão e apresenta deficiente proteção dos pequenos acionistas e stakeholders (Marques, 2008). Na tabela 2 apresentam-se uma síntese da adoção dos modelos de governo das sociedades e presença dos trabalhadores no órgão de supervisão em vários países. 
Tabela 2

Sistemas de administração e presença dos trabalhadores no órgão de supervisão em quinze países europeus

\begin{tabular}{|c|c|c|}
\hline País & $\begin{array}{c}\text { Sistema de } \\
\text { Administração }\end{array}$ & $\begin{array}{c}\text { Presença de trabalhadores } \\
\text { no órgão de supervisão }\end{array}$ \\
\hline Áustria & Dualista & Sim \\
\hline Bélgica & Monista & Não \\
\hline Dinamarca & Dualista & Sim \\
\hline Finlândia & Monista & Possível através dos acordos de empresas \\
\hline França & Monista & Possível através dos acordos de empresa \\
\hline Alemanha & Dualista & Não \\
\hline Grécia & Monista & Não \\
\hline Irlanda & Monista & Não \\
\hline Itália & Monista & Sim \\
\hline Luxemburgo & Monista & Aconselhamento \\
\hline Holanda & Dualista & Não \\
\hline Portugal & Monista & Sim \\
\hline Espanha & Monista & Não \\
\hline Suécia & Monista & \\
\hline Reino Unido & Monista &
\end{tabular}

Fonte: Silva et al., 2006

Aggarwal et al. (2009) argumentam que as características do país explicam as diferenças das classificações do governo das sociedades. Em Portugal, o sistema de administração mais utilizado é o modelo monista e não se verifica a presença de trabalhadores no órgão de supervisão.

\section{O GOVERNO DAS SOCIEDADES EM PORTUGAL}

Em Portugal a Comissão do Mercado de Valores Mobiliários $(\mathrm{CMVM})^{3}$ é a autoridade a quem compete regular e supervisionar o funcionamento dos mercados de valores mobiliários e a atividade de todas as entidades que intervêm nesses mercados, tendo autonomia financeira e administrativa www.cmvm.pt.

As principais normas legais que regulam o governo das sociedades em Portugal estão contidas no Código das Sociedades Comerciais (CSC), aprovado pelo Decreto-Lei $\mathrm{n}^{0}$ 262/86, de 2 de Novembro, objeto de sucessivas alterações, e no Código dos Valores Mobiliários (CVM), aprovado pelo Decreto-Lei no 486/99, de 13 de Novembro (Câmara, 2001). O CSC define os aspetos relacionados com o controlo e direção das sociedades, embora não se limite, às sociedades cotadas. O CVM

${ }^{3}$ A Comissão do Mercado de Valores Mobiliários (CMVM) foi criada pelo Decreto-Lei n. ${ }^{\circ}$ 142-A/91, de 10 de Abril. 
estabelece as consequências jurídicas para as sociedades abertas, como as de especiais exigências informativas para as sociedades e seus titulares de participações qualificadas (menções obrigatórias em atos externos, o dever de informação de participações qualificadas), ou as de proteção dos investidores (Câmara, 2001). Conforme disposto no art. $^{\circ} 405 .^{\circ}$ do (CSC), o governo das sociedades está entregue ao conselho de administração. Sendo um órgão que acumula funções de administração e de fiscalização possui, regra geral estrutura híbrida. Os diretores são nomeados de acordo com os estatutos, ou eleitos pelos acionistas, nunca podendo os seus mandatos exceder quatro anos. Em organizações com um capital social inferior a 200.000 euros, a gestão pode estar a cargo de um só administrador ${ }^{4}$ (Câmara, 2001).

Em outubro de 1999, a CMVM emitiu as primeiras recomendações sobre o governo das sociedades cotadas, dirigidas às sociedades emitentes de ações em mercado regulamentado e aos investidores institucionais, as quais vieram a conhecer novas edições em Dezembro de 2001, Novembro de 2003, em Novembro de 2005, tendo já em conta a revisão dos Princípios da OCDE aprovados em 2004, em 2007 e as últimas em 2013 (www.cmvm.pt).

A missão da CMVM é a de contribuir para assegurar a proteção dos investidores, promovendo a eficiência, equidade, segurança e a transparência do mercado de valores mobiliários (www.cmvm.pt). O enquadramento legal e os códigos de conduta do governo das sociedades servem para evitar erros que deixam de ser considerados atos irregulares para serem, mais tarde, rotulados de fraude pela existência de dolo ou máfé (Lourenço et al. 2008). A CMVM recomenda a criação de comités específicos de supervisionamento das diferentes áreas desde a nomeação de administradores, auditoria e revisão do plano de remunerações ou evolução dos mecanismos de governo (www.cmvm.pt). As recomendações têm conhecido uma evolução significativa, quanto ao seu conteúdo, e à envolvente regulamentar. A primeira edição destas recomendações "limitava-se a procurar que os emitentes de ações informassem o mercado sobre o grau de cumprimento das recomendações” (Pereira e Branco 2005).

Em 2001, o Regulamento n. ${ }^{\circ}$ 7/2001 da CMVM aderiu ao princípio “comply or explain” e propõe que as sociedades emissoras de ações admitidas à negociação em mercado regulamentado devem divulgar anualmente informações sobre diversos aspetos ligados ao governo das sociedades (www.cmvm.pt). Pereira e Branco (2005) salientam o facto de este regulamento obrigar as sociedades emissoras de ações a elaborar um

${ }^{4}$ Cfr. $n^{\circ} 2$ do artigo $390 .{ }^{\circ}$ CSC. 
relatório sobre o governo da sociedade, em anexo ao relatório anual de gestão, ou num capítulo separado.

Em 2003, ocorreu uma nova revisão de forma a tornar mais completo o relatório anual sobre o governo das sociedades mantendo-se contudo os fundamentos do Regulamento n. ${ }^{\circ}$ 7/2001 da CMVM e as linhas da filosofia "comply or explain" Esta revisão, valorizou o conceito de "administrador independente" e criou novos deveres de informação das sociedades, incluindo informação sobre os honorários pagos aos auditores e divulgação de informação obrigatória através de site na internet (Pereira e Branco, 2005; Câmara, 2007).

Em 2005 surgem novas modificações relacionadas com 0 aperfeiçoamento do sistema de fiscalização interna e o reforço da transparência das sociedades, o que se traduz, na prática, numa maior exigência informativa ao nível do relatório anual sobre o governo das sociedades (www.cmvm.pt). Estas novas recomendações da CMVM passam por sugerir; a criação de um gabinete de apoio ao investidor; eliminação das limitações ao exercício do voto, diretamente, por correspondência, ou por procuração; criação de um sistema interno de controlo para a deteção de riscos, em salvaguarda do seu património e em benefício da transparência; adoção de medidas para impedir o êxito de ofertas públicas de aquisição e o dever de respeitar os interesses da sociedade e seus acionistas (Serafim et al. 2010).

Em 2007 faz-se uma nova revisão em que um conjunto de recomendações conhece uma nova arrumação sistemática e passa a ser designado por "Código do Governo das Sociedades da CMVM". No mesmo ano, a CMVM aprovou o Regulamento n. ${ }^{\circ}$ 1/2007, com consequente revogação do Regulamento $\mathrm{n}^{\circ} .7 / 2001$. A revisão bienal do texto das "Recomendações da CMVM sobre Governo das Sociedades", levou a sucessivas modificações do Regulamento $n^{\circ}$ 7/2001 (Regulamentos da CMVM nos 11/2003, 10/2005 e 3/2006), com o propósito de adequar o enquadramento regulamentar e recomendatório às recomendações da Comissão Europeia e a revisão dos princípios da OCDE sobre o governo das sociedades (Tavares, 2006).

À semelhança do que acontece a nível da União Europeia em território Português a tendência é para recorrer às recomendações, em vez das obrigações. Na América a prática é o inverso, apostam na força da lei, através da lei SOX, para obrigar as empresas a boas práticas de transparência (Lourenço et al. 2008). Em Portugal existem algumas disposições ou recomendações que se assemelham às disposições previstas pela lei SOX, nomeadamente as recomendações da CMVM, alguns artigos previstos no Código das Sociedades Comerciais, algumas disposições do regulamento dos Revisores Oficiais de Contas, e mais recentemente através do Instituto Português de Corporate Governance (IPCG) que em janeiro de 
2013, aprovou um novo código de governo societário de iniciativa privada (Câmara et al. 2013).

O novo código do governo das sociedades da CMVM introduzido em 2013 tem um cômputo de 40 recomendações (Câmara et al. 2014). O objetivo das recomendações é o de procurar contribuir para a otimização do desempenho das sociedades e favorecer todas as pessoas cujos interesses estão envolvidos na atividade societária; investidores, credores e trabalhadores. Na tabela 3 apresentam-se as principais recomendações emitidas pela CMVM.

Tabela 3

Regulamentos nacionais

\begin{tabular}{|l|}
\hline Recomendações da CMVM - Regulamentos 7/2001 e 11/2003 \\
\hline - Divulgação de Informação \\
- Gabinete de apoio ao investidor \\
- Inexistência de restrições ao direito de voto e representação de acionistas \\
- Sistema de controlo Interno \\
- Inexistência de cláusulas defensivas que provoquem erosão do património da \\
sociedade \\
- Pluralidade de membros do Órgão de Administração \\
- Comissão do Órgão de Administração \\
- Divulgação da Remuneração do Orgão de Administração \\
- Membros da comissão de Remunerações Independentes \\
- Aprovação de planos de atribuição de acções ou opções em Assembleia Geral \\
\hline
\end{tabular}

Fonte: adaptado de www.cmvm.pt

A política seguida pela CMVM, através das Recomendações e Regulamentos que tem publicado, tem sido a de «comply or explain», pelo que as empresas são obrigadas a divulgar se, e em que medida, cumprem as recomendações ou então a explicar por que não o fazem. No entanto, começam a surgir algumas vozes em oposição a esta metodologia que consideram que deveria existir uma maior exigência legal (Serafim et al. 2010).

Em Portugal as boas práticas não são, impostas às empresas pelo que se deixa margem ao funcionamento espontâneo do mercado (Moreira, 2005). Neste sentido, a CMVM deixa em aberto possíveis retificações e ajustamentos ou aditamentos às suas recomendações, tendo em curso um projeto de revisão do seu código de governo das sociedades e do Regulamento N1/2010 (Câmara et al. 2013). Por força da pressão internacional, as empresas Portuguesas, especialmente as cotadas, têm vindo a sentir a necessidade da aplicação destes princípios, por via das alterações legislativas e regulamentares, pelo reconhecimento que têm da 
promoção de melhores práticas de gestão e pela competitividade que ajudam a criar (Santos, 2009).

Segundo Lourenço et al. (2008), os principais pilares para implementar o governo das sociedades em Portugal são; a visão estratégica, missão, valores, metas globais e o campo de objetivos e será segundo estes pilares que as empresas deverão estruturar o seu sistema de governo das sociedades e cumprirem com as recomendações da CMVM, UE e OCDE. Para avaliar o grau de adoção do governo das sociedades, Mckinzey (2004) realizou estudos, dos quais se pode concluir que; a Europa tem-se posicionado como referência mundial de governo das sociedades e em termos médios, a utilização do sistema de governo das sociedades subiu de 45\% em 1999 para 84\% em 2004 (Marques, 2008). Este facto reflete a crescente adoção dos modelos de governo das sociedades e a tendência para aumentar.

Em Portugal, na perspetiva de analisar a adesão e aferir o cumprimento das recomendações sobre o governo das sociedades, a CMVM realizou quatro inquéritos dirigidos às empresas cotadas no Mercado de Cotações Oficiais (MCO) ${ }^{5}$, os quais tiveram lugar nos anos de 1999, 2000, 2001 e 2002. Os inquéritos de 1999, 2000 e 2001 incidiram sobre as recomendações de 1999, enquanto o de 2002 teve como referência as recomendações atualizadas de 2001. O resultado do $4^{\circ}$ Inquérito da CMVM sobre Práticas Relativas ao governo das sociedades Cotadas no Mercado de Cotações Oficiais da Euronext Lisboa apresenta-se na tabela 4.

\section{Tabela 4}

Número de empresas cumpridoras e respetivo grau de cumprimento das recomendações do $4^{\circ}$ Inquérito da CMVM sobre Práticas Relativas ao governo das sociedades Cotadas no Mercado de Cotações Oficiais da Euronext Lisbon

\begin{tabular}{|r|r|r|r|r|r|r|r|r|r|r|r|r|}
\hline \multicolumn{10}{|c|}{ SOCIEDADES CUMPRIDORAS POR RECOMENDAÇ̃̃o $^{*}$} \\
\hline R1 & R2 & R3 & R4 & R5 & R6 & R7 & R8 & R9 & R10 & R11 & R12 & R13 \\
\hline 34 & 36 & 1 & 3 & 29 & 35 & 44 & 41 & 21 & 8 & 19 & 24 & 11 \\
\hline $73,9 \%$ & $78,3 \%$ & $2,2 \%$ & $6,5 \%$ & $63,0 \%$ & $76,1 \%$ & $95,7 \%$ & $89,1 \%$ & $45,7 \%$ & $36,4 \%$ & $41,3 \%$ & $52,2 \%$ & $78,6 \%$ \\
\hline
\end{tabular}

Fonte: www.cmvm.pt - $4^{\circ}$ Inquérito da CMVM sobre Práticas Relativas ao Governo das Sociedades Cotadas no Mercado de Cotações Oficiais da Euronext Lisboa

\footnotetext{
${ }^{5}$ Inquéritos de 1999, 2000 e 2001 - Bolsa de Valores de Lisboa e Porto (BVLP); Inquérito de 2002 - Euronext Lisboa.
} 
A evolução manifestada no cumprimento das recomendações do governo das sociedades deve-se segundo Câmara, (2012), á tradição, permanentemente e renovada, do direito das sociedades, e á intenção recentemente manifestada na área do direito dos valores mobiliários.

Relativamente à evolução do governo das sociedades em Portugal, vale a pena destacar também o estudo realizado pela Heidrick \& Struggles ${ }^{6}$ em 2004, acerca do governo das sociedades na Europa, onde se constata um atraso significativo de Portugal relativamente aos restantes países. Na dimensão que se reporta à análise dos órgãos de administração das empresas, o rating encontrado para Portugal foi mesmo o mais baixo; no entanto, apesar de se manter na $10^{\mathrm{a}}$ posição, foi o país que maior progresso registou (Moreira et al. 2008), figura 1.

\section{Figura 1}

\section{Comparação da Posição de Portugal na adoção do governo das sociedades}

Corporate governance ratings by country

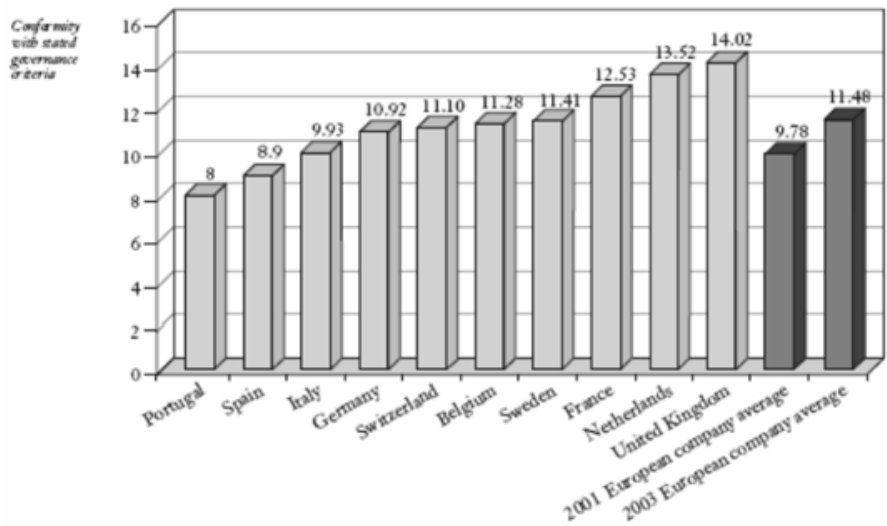

Fonte: Moreira et al., (2008)

Lourenço et al. (2008) consideram que Portugal evoluiu significativamente em termos de governo das sociedades, sendo considerado um País particularmente forte na adesão e aplicação do sistema nos últimos anos, já que passou da última posição, em 2003, para a sexta posição em 2008.

A evolução do governo das sociedades em Portugal vai no sentido de maior regulamentação e combate às fraudes, no sentido da implementação

\footnotetext{
${ }^{6}$ Heidrick \& Struggles, Is your board fit for the global challenge? Corporate Governance in Europe. http://www.heidrick.com/NR/rdonlyres/DACDA5C0-7DD54A8D-AE86A50A01CFCD57/0/HS_CorpGovEurope.pdf
} 
de códigos de ética e da sustentabilidade organizacional (Serafim et al. 2010). Segundo estes autores o que interessa é a transparência e de acordo com uma recente pesquisa divulgada pela Edelman (2010), a Trust Barometer 2010, a confiança e transparência - influenciam e reputação corporativa e exige que as empresas adotem uma abordagem multidimensional de seu envolvimento com os stakeholders.

De salientar também o "Relatório Católica Lisbon/AEM", realizado em 2013, pelo $4^{\circ}$ ano consecutivo, pelo Centro de Estudos Aplicados da Universidade Católica de Lisboa, a pedido da AEM Associação de Empresas Emitentes de valores cotados em mercado. O Relatório, além da sua formulação conceptual, envolveu um trabalho de recolha de dados relativo às práticas de governação seguidas pelas empresas com ações cotadas no mercado regulamentado português (Câmara et al. 2014). Denominado "Relatório sobre o Grau de Acolhimento de Recomendações Sobre o Governo das Sociedades em Portugal e Apuramento do Índice e Rating de Governo Societário Católica Lisbon/AEM”, analisou o grau de acolhimento de 20 das 40 recomendações, contidas no código do governo das sociedades da CMVM de 2013, por parte de 41 empresas, com ações cotada no mercado regulamentado português em 2013, do qual se apresenta um extrato do resultado das principais recomendações na tabela 5. 
Tabela 5

Percentagem de empresas com acolhimento às recomendações do governo das sociedades em 2013 em Portugal

\begin{tabular}{|c|c|c|c|}
\hline \multirow[b]{2}{*}{ Recomendações } & \multicolumn{3}{|c|}{$\begin{array}{l}\text { Percentagem de empresas de } \\
\text { acolhimento }\end{array}$} \\
\hline & $\begin{array}{l}\text { Todas as } \\
\text { empresas }\end{array}$ & PSI 20 & $\begin{array}{l}\text { Restantes } \\
\text { empresas }\end{array}$ \\
\hline $\begin{array}{l}\text { Supervisão e administração } \\
\text { - Criação de comissão que avalie os } \\
\text { administradores executivos individualmente } \\
\text { - Independentes como administradores não } \\
\text { executivos }\end{array}$ & $70,70 \%$ & $64,70 \%$ & $75,00 \%$ \\
\hline $\begin{array}{l}\text { Fiscalização } \\
\text { - Órgão de fiscalização a zelar para condições } \\
\text { adequadas na prestação de serviços }\end{array}$ & $90,20 \%$ & $93,10 \%$ & $87,50 \%$ \\
\hline $\begin{array}{l}\text { - Avaliação dos sistemas de controlo interno } \\
\text { pelo órgão de fiscalização }\end{array}$ & $95,10 \%$ & $100,00 \%$ & $91,70 \%$ \\
\hline $\begin{array}{l}\text { - A comissão de auditoria, o conselho geral e } \\
\text { de supervisão e o conselho fiscal pronunciam- } \\
\text { se sobre a auditoria interna }\end{array}$ & $79,50 \%$ & $81,30 \%$ & $78,30 \%$ \\
\hline $\begin{array}{l}\text { - Independências dos membros comissão de } \\
\text { remunerações }\end{array}$ & $70,00 \%$ & $68,80 \%$ & $70,80 \%$ \\
\hline $\begin{array}{l}\text { - Remuneração dos administradores não } \\
\text { executivos não depende do desempenho }\end{array}$ & $92,10 \%$ & $93,80 \%$ & $90,90 \%$ \\
\hline $\begin{array}{l}\text { - Componente variável da remuneração com } \\
\text { limite máximo }\end{array}$ & $52,60 \%$ & $87,50 \%$ & $27,30 \%$ \\
\hline $\begin{array}{l}\text { - Auditor externo verifica aplicação das } \\
\text { políticas de remunerações }\end{array}$ & $82,90 \%$ & $88,20 \%$ & $79,20 \%$ \\
\hline $\begin{array}{l}\text { - Auditor externo verifica eficácia do sistema } \\
\text { de controlo interno }\end{array}$ & $85,40 \%$ & $88,20 \%$ & $83,30 \%$ \\
\hline
\end{tabular}

Fonte: Adaptado do Relatório Católica Lisbon/AEM 2014

Segundo Câmara et al. (2014), o grau de acolhimento das recomendações mais relevantes do código de governo societário pelas empresas portuguesas cotadas em 2013 foi elevado, e superior comparando com os resultados dos anos anteriores. Este acolhimento é superior entre as empresas que compõem o PSI 20.

Pode dizer-se que a evolução das "Boas Práticas" do governo das sociedades em Portugal tem vindo a ser positiva, havendo, no entanto, um longo caminho a percorrer até que os mercados internacionais se sintam mais confortáveis a investir no país. Segundo Serafim at al. (2010), o caminho a percorrer dependerá da forma como os investigadores entenderem os modelos do governo das sociedades, estilos de liderança e particularidades culturais inerentes ao país.

Ao longo da última década são vários os estudos que reforçam a importância do tema defendendo que; a organização com um bom sistema de governo das sociedades tem menos probabilidade de ser afetada por questões de agência (Naseem et al. 2017); as práticas de governo das 
sociedades podem beneficiar os investidores ao permitir identificar, com alguma antecedência, as organizações com dificuldades financeiras (Darrat et al. 2016); as empresas com estruturas de governo das sociedades investem significativamente mais em formação dos seus funcionários, obtendo benefícios adicionais e melhores produtividades. A estrutura de governo das sociedades está fortemente associada ao bem-estar dos funcionários, em particular, a maior salário, menos horário de trabalho mensal e menor possibilidade de salários em atraso (Zhong, et al. 2017). Permite reduzir a "assimetria de informação" existente entre gerentes e Stakeholders e melhora de forma positiva a informação (Hill e Jones 1992) citado por Zhong et al. (2017).

Testes adicionais mostram que o governo das sociedades aumenta a produtividade do trabalho, a eficiência de custos principalmente em indústrias menos competitivas e em países em desenvolvimento aumenta o investimento em capital e o valor da empresa. Atrai investidores, particularmente quando a sobrevivência é ameaçada pela intensa competição Cosset et al. (2016). O nível de desenvolvimento económico e financeiro de um país e o nível de investimento influencia o governo das sociedades da empresa (Doidge et al. 2007). O governo das sociedades está associado a muitas questões éticas na forma de transparência, relacionamentos e otimização de problemas (Müller et al. 2016). A fim de minimizar os riscos, os credores exortam as empresas a aumentar a transparência e a divulgar a informações financeiras (Louizi e Kammoun, 2016). O governo das sociedades apela ao progresso como caminho para a mudança social e económica (Pargendler, 2016). Um bom governo das sociedades fornece à empresa uma vantagem competitiva no acesso a novos fundos, reduzindo riscos financeiros para investidores e do custo de capital percebido (LouizieKammoun,2016).

\section{CONSIDERAÇÕES FINAIS}

O Governo das sociedades tornou-se uma preocupação central do nosso tempo (Pargendler (2016). É um conceito que abrange várias áreas da economia e gestão o seu principal objetivo é respeitar os interesses de todos os stakeholder, através de uma gestão rigorosa baseada em códigos de boas práticas, na transparência da gestão e informação prestada e na responsabilidade dos órgãos de Administração. Visa ainda a equidade no tratamento dos stakeholders; alinhamento de interesses na organização; accountability (responsabilidade); sustentabilidade; responsabilidade social e ambiental e criar sistema de regulação de conflitos inter-agentes (Marques, 2008), que por si só evidenciam a importância e o crescente interesse do tema. Como refere Gonçalves, (2008), um bom governo das sociedades contribui para um crescimento sustentável das organizações. 
Apesar dos desenvolvimentos em todos os países comunitários, observa-se, uma grande diversidade de mecanismos e regulamentações, longe da desejável harmonização na matéria. No decurso da última década foram elaborados vários modelos de boas práticas de governo das sociedades e, ainda que dirigidas às sociedades cotadas, devem ser vistos como de interesse para todas as sociedades.

Em Portugal a adoção do sistema governo das sociedades, tem pouco mais de uma década, baseia-se nas recomendações e regulamentos emitidos pela CMVM e no contexto normativo emitido pelo CSC e CSM e tem sido adotado com algum sucesso por parte de algumas sociedades. Estudos vários evidenciam que apesar de uma adesão tardia, relativamente a outros países, Portugal tem vindo a crescer na utilização do sistema e dos códigos de boas práticas. O estudo desenvolvido permitiu concluir que a sua aplicação por parte das organizações é cada mais evidente, que as organizações em Portugal manifestam um continuado e crescente acolhimento das recomendações do governo das sociedades e o seu estudo sistemático contribui para um melhor conhecimento e aperfeiçoamento dos códigos de boas práticas. Estas conclusões contribuem e incentivam o desenvolvimento científico do governo das sociedades e simultaneamente proporcionam conhecimentos aos gestores, e promovem que um maior número de organizações o adote, numa perspetiva de mais-valias para o mercado e para a sociedade.

Como a implementação do sistema está sujeito a influências endógenas e exógenas, o fato de se tratar de um estudo de revisão bibliográfica, limita as conclusões e dificulta a sua generalização. Assim sugerem-se estudos empíricos longitudinais, de modo a testar e compreender a evolução e adequação do sistema governo das sociedades, no sentido de criar valor e sustentabilidade organizacional.

\section{REFERÊNCIAS BIBLIOGRÁFICAS}

Aggarwal, R.; I. Erel; R. Stulz; and R. Williamson (2009) Differences in Governance Practice Between U.S. and Foreign Firms: Measurement, Causes, and Consequences.” Review of Financial Studies, 22 (2009), 3131-3169.

Aggarwal, R.; I. Erel; M. Ferreira; and P. Matos. (2011) Does Governance Travel Around the World? Evidence from Institutional Investors.” Journal of Financial Economics, 100 (2011), 154-181.

Almeida, C. F., (2001) Prefácio a Responsabilidade Civil dos Administradores perante os Accionistas, de Caetano Nunes, Coimbra. Almeida, D. (2005) Gestão de Risco e Governo das Sociedades, Revista de Auditoria Interna, $\mathrm{n}^{\circ} 22$, Outubro/Dezembro. 
Alves, C.F., (2000) Deverão os Investidores Institucionais Envolver-se no Governo das Sociedades?, in Cadernos do Mercado de Valores Mobiliários, n. ${ }^{\circ} 8$

Alves, C. F. (2003) Os Investidores Institucionais e o Governo das Sociedades: Disponibilidade, Condicionantes e Implicações. Tese de Doutoramento. Faculdade de Economia da Universidade do Porto.

Alves, A.C.M.R. (2009) A Evolução da Auditoria Interna após a Lei SOX - Impactos Indirectos no caso português, Universidade de Aveiro

Alves, C. e Mendes, V. (2004) As Recomendações da CMVM Relativas ao Corporate Governance e a Performance das Sociedades, Caderno do Mercado de Valores Mobiliários (II Parte - Publicação de Estudos por ocasião do $10^{\circ}$ aniversário da CMVM), 12, pp. 57-88.

Alves, C. e Mendes (2009) "The Portuguese Governance Codes as Factor of Change in Rules and Practises" in Codes of Good Governance around the World, ed F. Lopez Iturriaga, Nova Science Publishers.

Ammann, M.; D. Oesch; and M. M. Schmid (2013) Product Market Competition, Corporate Governance, and Firm Value: Evidence from the EU Area. European Financial Management, 19 (2013), 452-469.

Andriof et al. (2002) The corporate governance on the perspective of the stakeholders; Havard Business Review. June, 2002. EUA

Baysinger, B., Butler, H. (1995) Corporate Governance and the Board of Directors: Performance Effects of Changes in Board Composition, Journal of Law, Economics, and Organization, 1, 101-124.

Beasley, M.S. (1996) An Empirical Analysis of the Relation Between the Board of Director Composition and Financial Statement Fraud, The Accounting Review, 71, pp. 443-465.

Bebchuk, L., Cohen, A., Ferrell, A. (2009) "What Matters in Corporate Governance?”, Review of Financial Studies 22, 783-827.

Becht, M., Bolton, P. e Röell, A. (2003) Corporate Governance and Control, in: Handbook of the Economics of Finance, Volume 1A, Amsterdam: North-Holland.

Bennis, Warren at al. (2008) Transparência: como criar uma cultura de valores essenciais nas organizações. Rio de Janeiro: Elsevier, Tradução de: Transparency.

Berle, A. \& Means, G. (2004) The Modern Corporation and Private Property. Corporate Governance - An International Review, Vol. 1, pp. 236-239. 1932.

Cadbury Committee (1992) Committee on the financial aspects of corporate governance (Sir Adrian Cadbury, chair (1992), Report (Gee and Company, Ltd, London).

Cadbury, A. (1997) Board Focus: the Governance Debate (Egon Zehnder International). 
Cadernos do IPCG (2001) Sobre Corporate Governance - Boas Práticas dos Órgãos de Administração das Sociedades $1^{\circ}$ fascículo 26 de Abril de 2011.

Câmara, P. (2001) O Governo das Sociedades em Portugal: Caderno do Mercado de Valores Mobiliários (II Parte - Publicação de Estudos por ocasião do $10^{\circ}$ aniversário da CMVM), 12, pp. 45-56.

Câmara, P. (2002) "Códigos de Governo das Sociedades, Cadernos do Mercado e Valores Mobiliários n. ${ }^{\circ}$ 15, 65-90; também publicado nos Cadernos de Auditoria Interna, ed. Banco de Portugal, Ano 6 n. ${ }^{\circ} 1$ (Outubro 2003), 6-51.

Câmara, P. (2007) "Modelos de Governo das Sociedades Anónimas”, em Jornadas em Homenagem ao Professor Doutor Raul Ventura. A Reforma do Código das Sociedades Comerciais, (2007), 197-258 = Reformas do Código das Sociedades, ed. IDET, Almedina (2007), 179242.

Câmara, P. et al. (2011) "O Governo das Organizações. A Vocação Universal do Corporate Governance”, Almedina, Coimbra.

Câmara, P. et al. (2012) "Código do Governo das Sociedades Anotado", Almedina, Coimbra.

Câmara, et al. (2014) Governo das Sociedades em Portugal em 2014 Relatório Católica Lisbon/AEM, Centro de Estudos Aplicados da Universidade Católica de Lisboa.

http://www.cgov.pt/images/stories/ficheiros/relatorio_catolica_lisbon_a em_governo_das_sociedades_em_portugal_2014.pdf

Chhaochharia, V.; Y. Grinstein; G. Grullon; and R. Michaely. (2012) "Product Market Competition and Agency Conflicts: Evidence from the Sarbanes Oxley Law.” Johnson School Research Paper Series No. 182012, Cornell University.

Cosset, J.C., Somé, H. Y., Valéry, P. (2016) Does Competition Matter for Corporate Governance? The Role of Country Characteristics, Journal of Financial and Quantitative analysis, Vol. 51, No. 4, Aug. 2016, pp. 1231_1267 COPYRIGHT 2016, MICHAEL G. FOSTER SCHOOL OF BUSINESS, UNIVERSITY OF WASHINGTON, SEATTLE, WA 98195 doi:10.1017/S0022109016000648

COSO (1992) Internal Control - Integrated Framework, http://www.coso.org/IC.htm, acesso em Junho de 2011.

Chintrakarn, P., Jiraporn, P., Tong, S., Chatjuthamard, P (2017) Exploring the Effect of Religious Piety on Corporate Governance: Evidence from Anti-takeover Defenses and Historical Religious Identification, Journal of Business Ethics (2017) 141:469-476 DOI 10.1007/s10551-0152677-2

Chtourou, S., Bédard, J., Courteau, L. (2001) Corporate Governance and Earnings Management, Working Paper, University of Laval, Quebec. 
Clikeman, P. (2003) Where Auditors Fear to Tread, International Auditor, 60, 75-79.

CCP [Código Civil Português]. Actualizado até à Lei n. ${ }^{\circ}$ 6/2006, de 27 de Fevereiro, incorporando Declaração de Rectificação 24/2006, de 17 de Abril. Disponível em http://www.portolegal.com/CodigoCivil.html.

CMVM - Comissão do Mercado de Valores Mobiliários, http://www.cmvm.pt

, A importância do Corporate Governance - Uma perspectiva institucional,

http://www.cmvm.pt/estudos_documentos/intervencoes/20001123.asp

CMVM - Comissão do Mercado de Valores Mobiliários (2005), Recomendações da CMVM sobre o Governo das Sociedades Cotadas, Lisboa: CMVM.

Cunha, V \& Martins, A. (2007) Uma Visão Económica da Questão do Governo das Empresas, Jornal de Contabilidade, $\mathrm{n}^{\circ} 367$.

Darrat, A., Gray, S., Park, J.C., Wu, Y. (2016) Corporate Governance and Bankruptcy Risk, Journal of Accounting, Auditing \& Finance 2016, Vol. 31(2) 163-202.

Dechow, P., Sloan, R., Sweeney, A. (1996) Causes and Consequences of Earnings Manipulation: An

Analysis of Firms Subject to Enforcement Action by the SEC, Contemporary Accounting Research, 13, pp. 1-36.

Doidge, C.; G. A. Karolyi; and R. Stulz. (2007) Why Do Countries Matter So Much for Corporate Governance.”Journal of Financial Economics, $86,1-39$.

Deloitte (2003) Lei Sarbanes-Oxley: Guia para melhorar a governança corporativa latravés de eficazes controles internos. Brasil.

Duarte, T. A. (2008) O Governo das Sociedades (Corporate Governance) Análise do desempenho das Sociedades Cotadas em Bolsa Respondentes ao $4^{\circ}$ Inquérito da CMVM Sobre Práticas relativas ao Governo das Sociedades, Dissertação de mestrado, apresentada na Universidade Técnica de Lisboa.

Duarte, P. (2006) Capital de Risco - Análise da Indústria em Portugal, Dissertação de mestrado submetida no ISCTE para obtenção do grau de mestre em Finanças

Eisenberg, Melvin A., (1999) "The Prospects for Global Convergence of Corporate Governance", in XXIV Annual Conference of the International Organization of Securities Commissions-Panel 5 "Corporate Governance of Public Companies in a Context of Growing Cross-Border Investment".http://www.cmvm.pt/NR/exeres/3DC0A870BE65-4811-B091 E674E3E3971E.htm

Eighme, J., Cashell, J. (2002) Internal Auditors' Roles in Overcoming the Financial Reporting Crisis, International Auditing, 17, 3-10. 
Ferreira, A.G (2005) Corporate Governance - Um desafio para a modernização sustentável das empresas, af@plmj.pt

Giroud, X., and H. M. Mueller (2011) Corporate Governance, Product Market Competition, and Equity Prices. Journal of Finance, 66, 563600.

Goodwin, J. (2003) The Relationship Between the Audit Committee and the Internal Audit Function:

Evidence from Australia and New Zealand, International Journal of Auditing, 7, 263-276.

Goodwin, J., Yeo, T. (2001) Two Factors Affecting Internal Audit Independence and Objectivity:

Evidence from Singapore, International Journal of Auditing, 5, 107-125.

Gomes, E. (2007) A importância do controlo interno. Disponível em http://www.jmmsroc.pt/downloads/10anos/11.pdf.

Gonçalves, A. (2008) A evolução das Metodologias de Auditoria, Revisores e Auditores. https://ria.ua.pt/handle/10773/3261

Hala, N. (2003) Sherron Watkins: If Capitalists Were Angels, International Auditor, 60, 38-43.

Heidrick \& Struggles (2003) Is your board fit for the global challenge? Corporate Governance in Europe, London 2003, http://www.heidrick.com/NR/rdonlyres/DACDA5C0-7DD5-4A8D-

AE86-A50A01CFCD57/0/HS_CorpGovEurope.pdf

Hermalin, B., Weisbach, M. (2003) Boards of Directors as an Endogenously Determined Institution: A

Survey of the Economic Literature, Economic Policy Review, 9, pp. 7-26.

Instituto Português de Corporate Governance - OBJECTIVOS E PLA_O

DE ACTIVIDADES 2007-2010 - www.cgov.pt

Jensen, M.C., Meckling, W. (1976) Theory of the Firm: Managerial

Behavior, Agency Costs and Ownership Structure, Journal of Financial Economics, 3, 4, pp. 305-360.

Jensen, M. C. (2001) Value Maximization, Stakeholder Theory, and the Corporate Function. European Financial Management, 7, 297-317.

Karuna, C. (2010) Industry Product Market Competition and Internal Corporate Governance. Working Paper, University of California at Irvine.

Katmon, N., Farooque, O. A. (2017) Exploring the Impact of Internal Corporate Governance on the Relation Between Disclosure Quality and Earnings Management in the UK Listed Companies, Journal of Business Ethics (2017) 142:345-367 - DOI 10.1007/s10551-015-27528

Klein, A. (2002) Audit Committee, Board of Director Characteristics, and Earnings Management, Journal of Accounting and Economics, 33, pp. 375-400. 
Krishnan, G. (2003) Does Big 6 Auditor Industry Expertise Constrain Earnings Management?, Accounting Horizons, 17 (Suppl), 1-16.

Lourenço, M. et al. (2008) Corporate governance - factor de prevenção da fraude contabilística, Revista TOC 101 - Agosto 2008

Louizi, A., Kammoun, R. (2016) Evaluation of corporate governance systems by credit rating agencies, J Manag Gov (2016) 20:363-385 DOI 10.1007/s10997-015-9331-3

Mattedi, L. (2006) Como a Governança Corporativa pode ajudar no fortalecimento do Mercado de Capitais Brasileiro.

Marques, C. A. (2008) Corporate Governance, apontamentos, Universidade de Aveiro

Marques, M. (2008) O que é o "Corporate Governance"; Revista de Auditoria Interna, $\mathrm{n}^{\circ} 17$, Outubro/Dezembro.

Martin, D., Aldhizer, G., Campbell, J., Baker, A. (2002) When Earnings Management Becomes Fraud,

International Auditing, 17, 14-20.

Martins, A. M. V. e Moutinho, N.F.L (2010) “Accruals” Discricionários e o Governo das Sociedades: Uma Aplicação às Empresas Cotadas no Mercado Bolsista Português.

McKinsey \& Company (2004) Global Investor Opinion Survey, McKinsey \& Company.

https://extranet.sioe.org/uploads/isnie2013/krafft_qu_quatraro_ravix.pdf

Moreira, J. M., Gonçalves, H., Oliveira, G. A (2008) Corporate Governce em Portugal http://www.eben-spain.org/docs/Papeles/XII/Jose_Manuel_Moreira_y_otros.pdf

Moreira, J. (2005) Piecewise Linear Accruals Models: Do They (Really) Control for the Asymmetric Recognition of Gains and Losses? Working Paper, FEP, Porto.

Müller, R. Turner, J.R. Andersen, E.S., Shao, J., Kvalnes, O. (2017) Governance and Ethics in Temporary Organizations: The Mediating Role of Corporate Governance, Project Management Journal, Vol. 47, No. 6, 7-23 2016 by the Project Management Institute Published online at www.pmi.org/PMJ

Naseem, M. A., Zhan, H. Malik, F., Rehman, R. (2017) Capital Structure and Corporate Governance The Journal of Developing Areas Volume 51 No. 1 Winter 2017

OECD/ Corporate Governance Committee (2011) "Peer Review. Board Practices: Incentives and Governing Risks".

OCDE, (1999) OCDE principles of Corporate Governance, http://www.oecd.org/daf/governance/ principles.htm

Pargendler, M., (2016) The Corporate Governance Obsession, The Journal of Corporation Law Vol. 42:2 
Peasnell, K.V., Pope, P., Young, S. (2000) Board Composition and Earnings Management: Do Outside

Directors Constrain Abnormal Accruals? Working Paper, University of Lancaster, UK.

Pereira, G.\& Branco, C. (2005) As Novas Regras sobre Governo das Sociedades ("Corporate Governance")

http://www.cuatrecasas.com/media_repository/docs/eng/newsletter_soc ietario_novembro_2005.pdf

Pinheiro, J. (2008 a) Auditoria Interna - Manual Prático para Auditores Internos - Uma abordagem proactiva e a evolução necessária, Editora Rei dos Livros.

Pinheiro, J. (2008 b) Simbiose entre os princípios de boa governação e o controlo interno, Revista de Auditoria Interna, nº 32 , Outubro/Dezembro.

Pinheiro, J (2008 c) O Inegável valor da auditoria a partilha do conhecimento, Revista de Auditoria Interna, ${ }^{\circ} 30$, Abril/Junho.

Pires, A. (2008) Impacto da lei Sarbanes - Oxley no Sistema de Controlo Interno das empresas cotadas nos EUA - O caso Português; Mestrado em Contabilidade e Auditoria; Universidade Aberta.

Santos e Barbosa (2010) Sustainable Governance - Empresas Portuguesas no Contexto Internacional, Sam Research Eduardo Gai.

Santos, J.A. (2009) “Corporate Governance”Desenvolvimentos recentes e a realidade Portuguesa, Dissertação de mestrado, Universidade Aberta

Scarbrough, D., Rama, D., Raghunandan, K. (1998) Audit Committee Composition and Interaction with

Internal Auditing: Canadian Evidence, Accounting Horizons, 12, 51-62.

Scott, W. R. (2014) Institutions and organizations: Ideas, interests, and identities. Los Angeles, CA: SAGE Publications, Inc.

Silva, A. S., Vitorino, A., Alves, C. F., Cunha, J. A. da e Monteiro, M. A. (2006) Livro Branco sobre Corporate Governance em Portugal, Instituto Português de Corporate Governance.

Serafim, E. e Quelhas, G. Alledi, C (2010) Histórico e Fundamentos da Governança Corporativa - Contribuições para a sustentabilidade das Organizações - VI Congresso Nacional em Excelência em Gestão Niteroi - Brasil 5,6 e 7 de Agosto de 2010

Soares, V. M. (2005) The objectives of and expectations towards higher education in the changed societal context and its implications for governance - A personal overview. Higher Education.

Sousa, O. (2007) Auditoria Interna $\mathrm{n}^{0} 31$ Revista trimestral - Fórum de auditoria interna - evolução para além da Sarbanes - Oxley.

Tavares, C. (2006) Evolução e alterações no Governo das Sociedades. http://recipp.ipp.pt/bitstream/10400.22/313/1/PeDrO_SiLvA_MAUD_201 1.pdf 
Tavares, C. (2015) CMVM- Apresentação à Comissão Parlamentar de Orçamento, Finanças e Administração Pública. http://www.cmvm.pt/pt/Comunicados/Intervencoespublicas/Documents/Apresenta\%C3\%A7\%C3\%A3oComiss\%C3\%A3o Parlamentar\%20COFAP\%2021.04.2015_v23abr2015.pdf

Thomsen, S. \& Pederse, T. (1995) European models of corporate governance. Denmark:

Institute of International Economics and Management. Copenhagen Business School, (Working Paper, 4-95).

Tirole, J. (2001) Corporate Governance. Econometrica. Vol. 69, nº 1, pp. 1-35.

United Nation Conference on Trade and development (2006) Guidance on Good Pratice in Corporate Governance Disclosure, United Nations New York and Geneva.

Xie, B., Davidson, W., DaDalt, P. (2003) Earnings Management and Corporate Governance: The Roles

of the Board and the Audit Committee, Journal of Corporate Finance, 9, pp. 295-316.

Zingales, L. (1997) Corporate Governance. National Bureau of Economic Research, Cambridge, NBER Working Paper Series.

Zhong, N. Wang, S., Yang, R. (2017) Does Corporate Governance Enhance Common Interests of Shareholders and Primary Stakeholders?, Journal of Business Ethics (2017) 141:411-431 DOI 10.1007/s10551-015-2702-5

, Recomendações da CMVM sobre o Governo das Sociedades

Cotadas, Dezembro de 2001,

http://www.cmvm.pt/recomendacoes_e_orientacoes/recomendacoes/soc cot/indice.asp

, Recomendações da CMVM sobre o Governo das Sociedades Cotadas, Novembro de 2003,

http://www.cmvm.pt/recomendacoes_e_orientacoes/recomendacoes/soccot _nov2003/indice.asp

, $4^{\circ}$ Inquérito Sobre Práticas Relativas ao Governo das Sociedades

Cotadas no Mercado de Cotações Oficiais da Euronext Lisbon, http://www.cmvm.pt/estudos_documentos/estudos/inquerito_soc4/inquerit o4.asp

Governo das Sociedades em Portugal em 2012 - Relatório Católica Lisbon/AEM, Centro de Estudos Aplicados da Universidade Católica de Lisboa.

https://www.clsbe.lisboa.ucp.pt/pt-pt/system/files/assets/files/catolica aem_corporategovernance_relatorio_2013.compressed.pdf 
, Governo das Sociedades em Portugal em 2014 - Relatório Católica Lisbon/AEM, Centro de Estudos Aplicados da Universidade Católica de Lisboa.

http://www.cgov.pt/images/stories/ficheiros/relatorio_catolica_lisbon_aem _governo_das_sociedades_em_portugal_2014.pdf 